\title{
EVALUATION OF THE CORROSION INHIBITIVE BEHAVIOUR OF PAWPAW FLUID ON A315 MILD STEEL AND A304 STAINLESS STEEL IN $\mathrm{H}_{2} \mathrm{SO}_{4}$ MEDIUM
}

\author{
Ayoola A. Ayodeji ${ }^{1, \bowtie}$ Fayomi O. Sunday ${ }^{2}$, Akande I. Godwin ${ }^{3}$ \\ and Mgbahurike F. Chinemerem ${ }^{1}$ \\ ${ }^{1}$ Chemical Engineering Department, Covenant University, Ota, Ogun State, Nigeria \\ ${ }^{2}$ Mechanical Engineering Department, Covenant University, Ota, Ogun State, Nigeria \\ ${ }^{3}$ Mechanical Engineering Department, University of Ibadan, Ibadan, Oyo State, Nigeria \\ ${ }^{\square}$ Corresponding Author: ayodeji.ayoola@covenantuniversity.edu.ng
}

\begin{abstract}
In this research work, the evaluation of the corrosion inhibitive performance of pawpaw fluid on A315 mild and 304 stainless steels in $0.5 \mathrm{M} \mathrm{H}_{2} \mathrm{SO}_{4}$ (through weight loss approach) was investigated. The investigation involved the effects of variation in the inhibitor concentrations $(0-10 \% \mathrm{vol} / \mathrm{vol})$ on weight loss, corrosion rate, inhibitor efficiency and the morphological structure of the metal samples. The weight-loss method involved the subjection of metal samples to the corrosion process in the acidic medium for 21 days. The results of both weight loss and corrosion rates revealed that pawpaw fluid inhibitor with a concentration of $10 \% \mathrm{vol} / \mathrm{vol}$ gave the highest inhibitor efficiency of $89.9 \%$ and 87.1\% for A315 mild and A304 stainless steels respectively. Also, results obtained showed that Langmuir adsorption isotherm accurately described the behavior of the adsorption mechanism and the physical adsorption (spontaneous) nature of the inhibitor was justified by the negative values of $\Delta \mathrm{G}_{\mathrm{ads}}$. Chemical composition results and the SEM analysis revealed that stainless steel has better corrosion resistance performance in $0.5 \mathrm{M} \mathrm{H}_{2} \mathrm{SO}_{4}$ medium compared to mild steel (under the same experimental condition).
\end{abstract}

Keywords: Corrosion, Inhibitor, Mild Steel, Pawpaw Fluid, Stainless Steel.

RASĀYAN J. Chem., Vol. 14, No.4, 2021

\section{INTRODUCTION}

Metals are the most ordinarily utilized group of materials in the most engineering industry. However, the life expectancy of these materials and their alloys is generally hampered by a naturally occurring phenomenon called corrosion. ${ }^{1}$ The corrosion of metals has a well pronounced negative impact on the physical, mechanical and chemical properties of these metals. In addition, corrosion of metals has financial and social impacts on man and the environment; among these is a threat to the wellbeing and safety of human beings that reside in the vicinity of business locations or working areas where metal failure resulting from corrosion occurred. ${ }^{2}$

Mild steel and stainless steel have wide areas of industrial and domestic applications, as a result of their availability, cost-effectiveness and relatively good physical properties. These are materials of choice used in the designing of reaction vessels (reactors), storage tanks, keys, gates etc. Many industries under manufacturing utilized these steels (as vessels) in performing their various activities that involve the utilization of acidic solutions in varying concentrations. The major problem associated with the use of mild and stainless steels is their susceptibility to corrosion especially in acidic regions. ${ }^{3-5}$

Two major approaches are generally adopted in the safeguarding of steels from corrosion; these are cathodic protection and corrosion inhibition. Cathodic protection operation is based on the introduction of a sacrificial anode and this is actualized through the adoption of the metal to be protected to be placed as 'cathode' in an electrochemical cell while the corroding metal (sacrificial metal) is made as anode. ${ }^{6-8}$ Corrosion inhibition involves the subjection of both the corrodibility metal (electrode) and the corrosive environment (electrolyte) to a chemical substance (corrosion inhibitor). That is, corrosion inhibitors are chemical substances that are introduced in minute quantity to the corrosive medium to resist or reduce corrosion reaction process. ${ }^{9}$ An inhibitor simply retards corrosion reaction by reducing (or preventing) the

Rasayan J. Chem., 14(4), 2506-2515(2021)

http://dx.doi.org/10.31788/RJC.2021.1446352

This work is licensed under a CC BY 4.0 license. 
activity of certain reactants on the metal surface, and thereby promoting a protective film formation that usually forms a barrier on the metal surface through the adsorption process. ${ }^{9-11}$

Recently, the trend on the use of corrosion inhibitors has shifted to naturally occurring and environmentally friendly chemical materials, popularly referred to as "green inhibitors", due to easy accessibility and nontoxic effect such organic inhibitors have on both human beings and the environment. ${ }^{12-17}$ Extracts from different parts of a pawpaw plant are good examples of green inhibitors. Hence, in this research work, the pawpaw fluid extract will be investigated as a corrosion inhibitor, its corrosion efficiency and adsorption behavior would be established.

\section{EXPERIMENTAL}

The materials used in the course of this research work include A315 mild steel, A304 stainless steel, emery paper and the pawpaw fluid extract. The equipment used is Autolab PGSTAT 101 Metrohm potentiostat/galvanostat (with NOVA programming), XRF spectrometer (Thermo scientific ARL OPTIM'X 166) and Jeol scanning electron microscope (JSM - 7600F UHR Analytical FEG SEM)

\section{Preparations of the Metal Samples and Inhibitor}

The mild and stainless steels were cut into small uniform samples of $2.3 \mathrm{~cm} \times 2.3 \mathrm{~cm} \times 0.1 \mathrm{~cm}$ each. The chemical compositions of the metals used are given in Table-1. The metal samples were polished (to ensure smooth surface) using emery paper, washed in dilute acetone (to remove particles and all forms of debris) and then rinsed in distilled water (to ensure no particle or chemical substance remained on the surface). The pure form of pawpaw fluid extract (inhibitor) was obtained from over-ripe pawpaw fruit through mashing and filtration before being kept in the refrigerator. Phytochemical analyses were carried out to establish the chemical constituents of the fluid inhibitor. Some of the phytochemical compounds (antioxidants) tested for include tannins, alkaloids, sterols and glycosides.

Table-1: Compositions of A315 mild and A304 Stainless Steels

\begin{tabular}{c|c|c}
\hline & \multicolumn{2}{|c}{$\%$ Composition } \\
\hline Element & Mild Steel & Stainless Steel \\
\hline $\mathrm{Cr}$ & 0.098 & 18.110 \\
\hline $\mathrm{Ni}$ & 0.022 & - \\
\hline $\mathrm{Mn}$ & 0.250 & 0.276 \\
\hline $\mathrm{Al}$ & 0.540 & 1.201 \\
\hline $\mathrm{C}$ & 1.135 & 70.320 \\
\hline $\mathrm{Fe}$ & 96.800 &
\end{tabular}

\section{Weight Loss, Corrosion Rate, Inhibitor Efficiency and Porosity Analysis}

$100 \mathrm{~mL}$ of $0.5 \mathrm{M} \mathrm{H}_{2} \mathrm{SO}_{4}$ (with $98 \%$ purity) was used as the acidic corrosion test medium in this research The weight loss method involves the weighing of the metal samples before and after corrosion in the acidic medium, within a specified range of time $(0-21$ days $)$. The difference in weight was the weight loss due to corrosion. Five batches of experiments, based on the varied inhibitor concentrations of pawpaw fluid $(0-$ $10 \% \mathrm{vol} / \mathrm{vol})$, were formulated as the acidic media. Each of the prepared metal samples was completely suspended in the specified acidic medium for corrosion to occur within the required time frame.

Weight loss (WL), corrosion rate (CR), Inhibition efficiency (IE) and surface coverage $(\theta)$ were obtained using Equations $1-4$.

$$
\begin{aligned}
& \mathrm{WL}=\mathrm{W}_{\mathrm{b} 4 \text { Corr }}-\mathrm{W}_{\text {aftCorr }} \\
& \mathrm{CR}(\mathrm{mm} / \mathrm{yr})=87.6 \times \frac{\mathrm{W}}{\mathrm{D} \times \mathrm{AxT}} \\
& \mathrm{IE}(\%)=\left(1-\frac{\mathrm{CR}_{\text {with }}}{\mathrm{CR}_{\text {without }}}\right) \times 100 \\
& \theta=\frac{\mathrm{CR}_{\text {without }}-\mathrm{CR}_{\text {with }}}{\mathrm{CR}_{\text {without }}}
\end{aligned}
$$

Where $\mathrm{W}_{\mathrm{b} 4 \text { Corr }}=$ metal weight before corrosion in milligrams, $\mathrm{W}_{\mathrm{aftCorr}}=$ metal weight after corrosion, $\mathrm{D}$ $=$ density of metal in $\mathrm{g} / \mathrm{cm}^{3}, \mathrm{~A}=$ total surface area of the sample in $\mathrm{cm}^{2}, \mathrm{~T}=$ exposure time in hours, $\theta=$ surface coverage of pawpaw fluid extract inhibitor on the metal coupon, $\mathrm{CR}_{\text {without }}=$ corrosion rate of the metal sample without inhibitor and $\mathrm{CR}_{\text {with }}=$ corrosion rate of the metal sample with inhibitor. 


\section{Adsorption of Pawpaw Fluid Inhibitor}

The adsorption of the pawpaw fluid inhibitor, as an adsorbate on the metal surface, was evaluated by fitting the data obtained from weight loss into different adsorption isotherms (using Equations 5 - 8), to establish the appropriate adsorption isotherm that rightly described the adsorption mechanism.

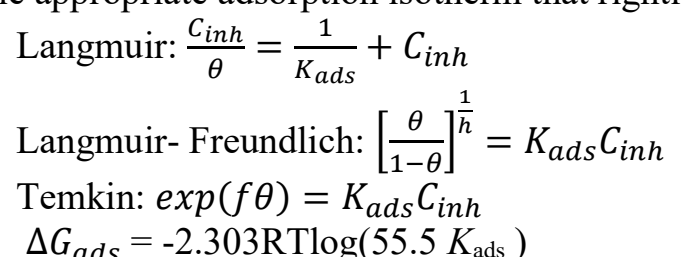

Where $K_{a d s}=$ Adsorption equilibrium constant, $C_{i n h}=$ concentration of the pawpaw fluid inhibitor in the acidic medium, $f=$ factor of energetic inhomogeneity, $h=$ heterogeneity parameter $(0<\mathrm{h}<1), R=$ gas constant $\left(8.314 \mathrm{~J} \mathrm{~K}^{-1} \mathrm{~mol}^{-1}\right), T$ is absolute temperature $(\mathrm{K})$ and $\Delta G_{a d s}=$ change in Gibbs free energy.

\section{SEM Analysis of the Metal Samples}

Using Jeol scanning electron microscope (JSM - 7600F UHR Analytical FEG SEM), scanning electron microscopy analysis was performed to evaluate the surface structures of the metal samples subjected to corrosion (with and without inhibitor) during the corrosion process.

\section{Phytochemical Analyses on the Pawpaw Fluid Inhibitor}

\section{RESULTS AND DISCUSSION}

The chemical compounds analyzed in pawpaw fluid inhibitor are as shown in Table-2.

\section{Weight Loss Results}

Figures- 1 and 2 revealed the weight loss results obtained from the corrosion of mild steel and stainless when subjected to corrosion. From the graphs, it can be convincingly seen that as the pawpaw fluid inhibitor concentration increased, a significant decrease in the metal weight loss was observed. Also, the plots revealed that that the weight loss decreased as the exposure time increased. These indicated that pawpaw fluid (introduced as corrosion inhibitor) hindered the corrosion reaction. And this act can be traced to the presence of phytochemicals which are anti-oxidants in nature ${ }^{18}$. That is, the natural phenomenon of the corrosion process, an oxidation reaction process, was resisted by these anti-oxidants in the inhibitor ${ }^{19}$. Considering the effect of the exposure time of metal to corrosion, it could also be observed that as the exposure time to corrosion increased, the weight loss of metal increased.

Table-2: Structures of the Compounds in Pawpaw Fluid Inhibitor (as reported in Literature)

Compound




\section{RASĀYAN J. Chem.}

Vol. 14 | No. 4 |2506-2515| October- December | 2021
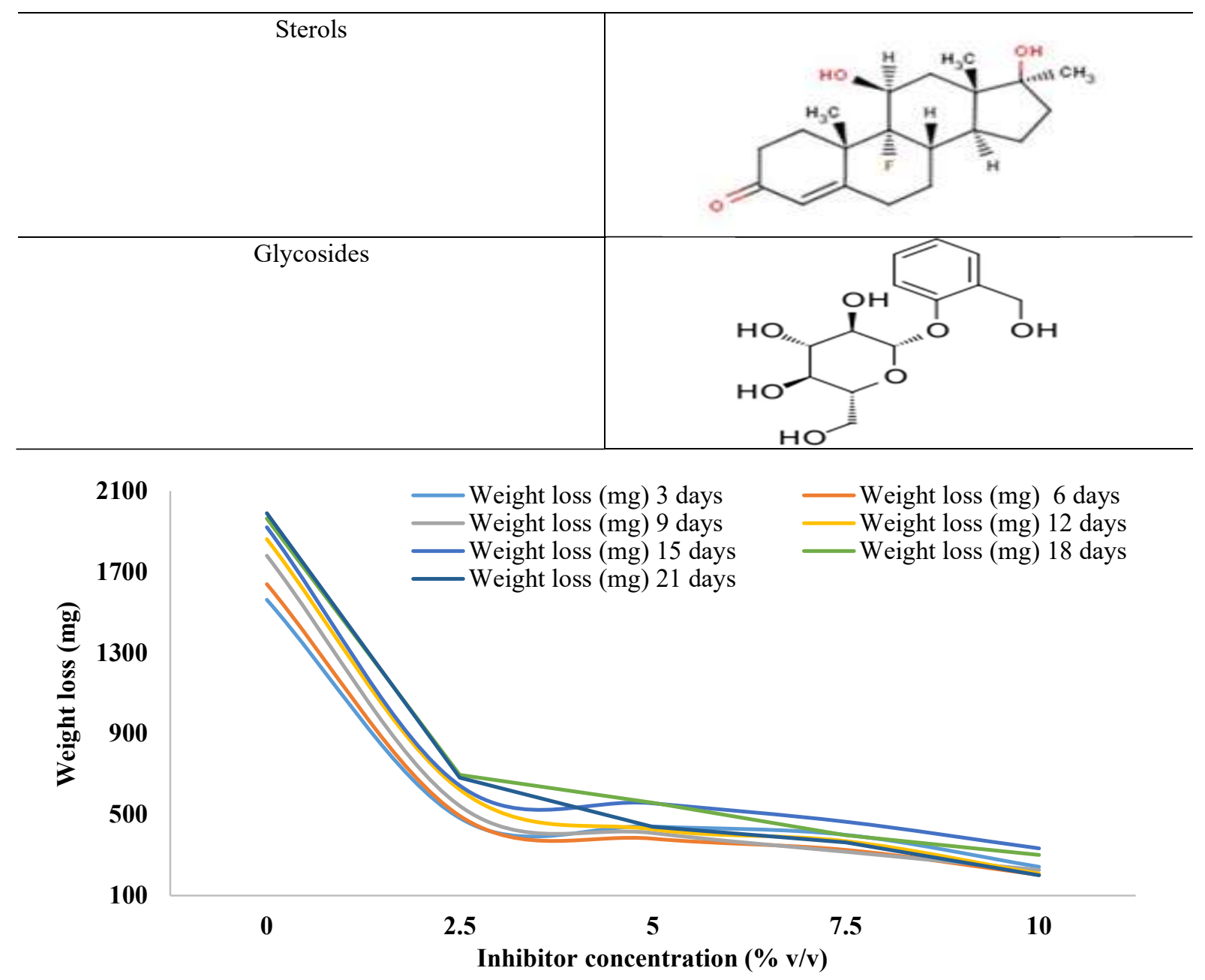

Fig.-1: Weight Loss Obtained From the Corrosion of Mild Steel at a Varied Inhibitor Concentration

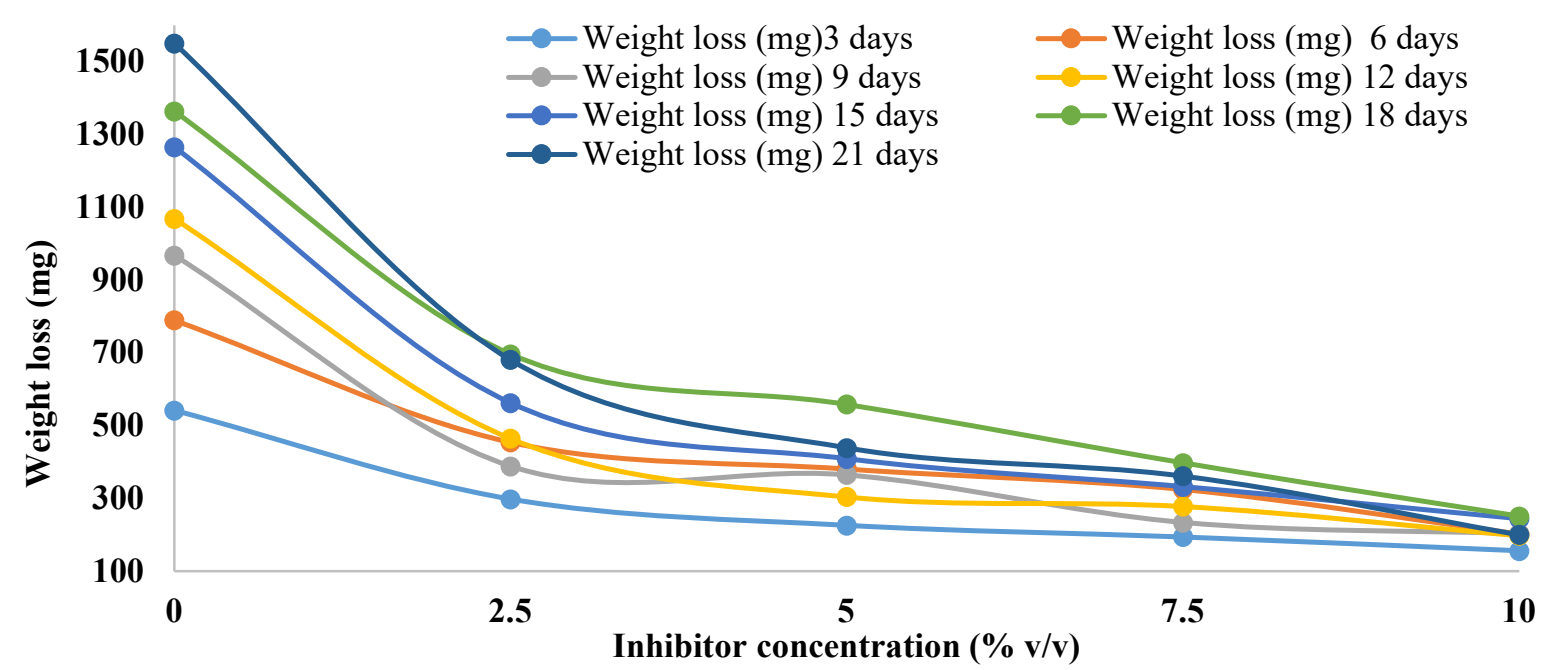

Fig.-2: Weight Loss Obtained from the Corrosion of Stainless Steel at a Varied Inhibitor Concentration

Inhibitor Efficiency of the Pawpaw Fluid Inhibitor

Figures-3 and 4, the calculated inhibitor efficiency of the inhibitor increased with an increase in the concentration of the inhibitor in the corrosive environment. Also, the efficiency increased as the 
concentration of the inhibitor used increased and a significant increase was noticed within the $1 \mathrm{st}-15$ days of exposure time to corrosion. A result trend that further established the good performance of the pawpaw fluid as a corrosion inhibitor (as also noticed in the case of weight loss).

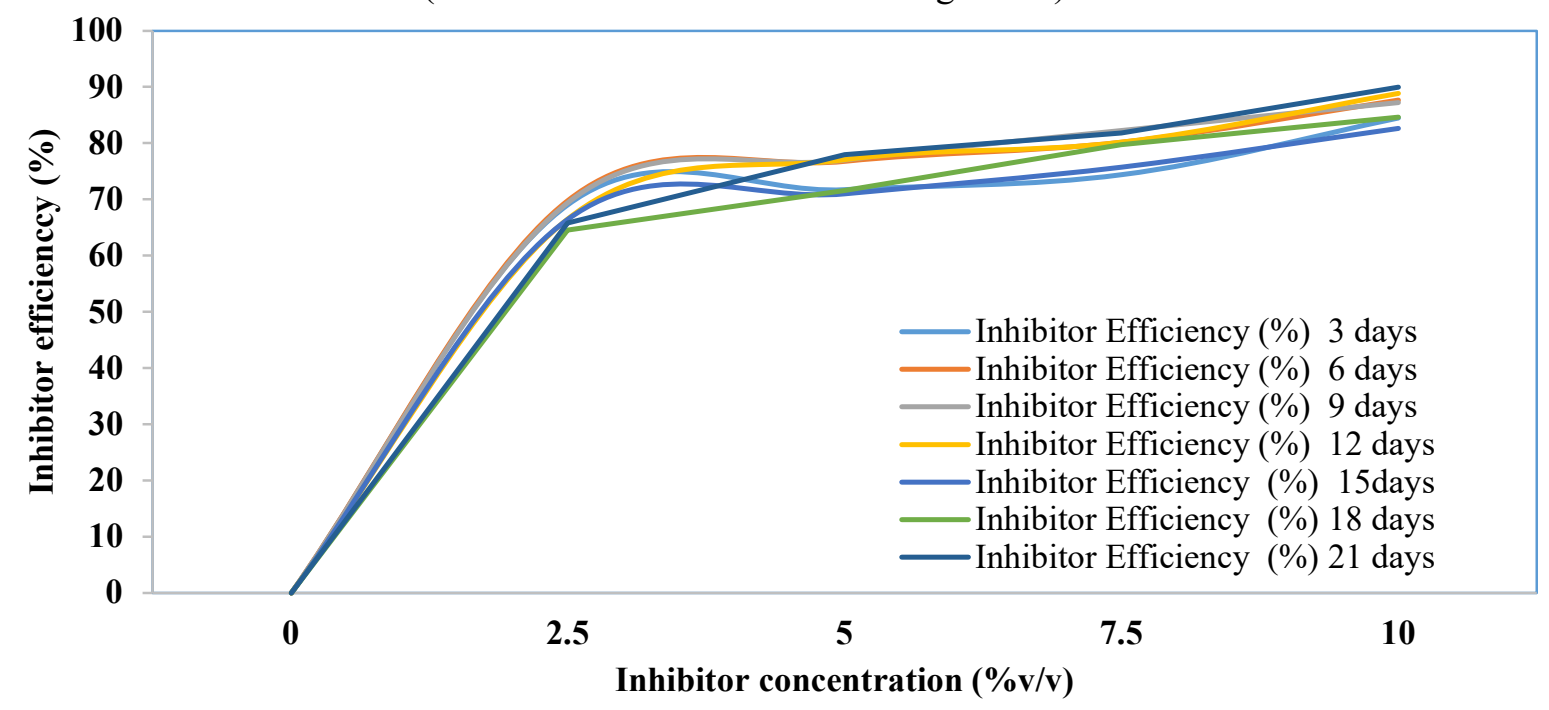

Fig.-3: Inhibitor Efficiency with Exposure Time for Mild Steel at Varied Inhibitor Concentrations

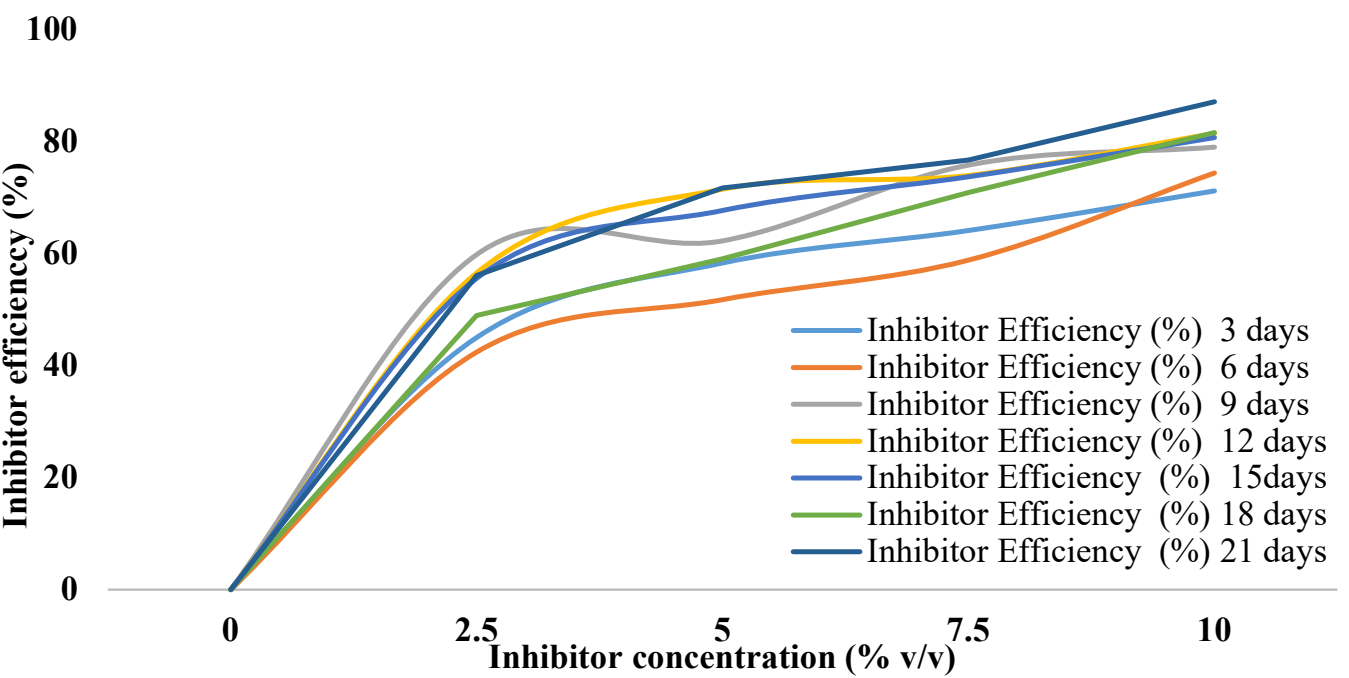

Fig.-4: Inhibitor Efficiency with Exposure Time for Stainless Steel at Varying Inhibitor Concentrations

Comparatively, Figs.-1 and 4 revealed that the weight loss of the mild steel was higher than the values obtained from the stainless steel, under the same experimental condition. And also the inhibitor efficiency of the mild steel was lower than that of the stainless steel, under the same experimental condition. That is, the corrosion resistance of the mild steel was lower than that of the stainless steel. This could be explained in terms of the main elemental constituents of the two forms of steel (Table-1). Nickel and Chromium, good corrosion resistance materials, were $0.022 \%$ and $0.098 \%$ (respectively) in mild steel but they were $8.320 \%$ and $18.11 \%$ (respectively) in stainless steel. Also, iron (the base metal) is known to be very susceptible to corrosion and its percentage content was higher in mild steel $(96.80 \%)$ compare to its value of $70.32 \%$ in stainless steel. These accounted for the results obtained in Fig.-5, with the corrosion rate of mild steel being higher than that of the stainless steel under the same conditions.

\section{Adsorption Isotherm Results}

The experimental data obtained from the subjection of the metals (mild steel and stainless steel) to corrosion was used to establish the appropriate adsorption isotherm that described the adsorption process of the 
RASĀYAN J. Chem.

Vol. 14 | No. 4 |2506-2515| October- December | 2021

inhibitor on the surface of the two metals. Langmuir isotherm (Eqn.-5) was found to fit the adsorption mechanism for both mild steel and stainless steel.

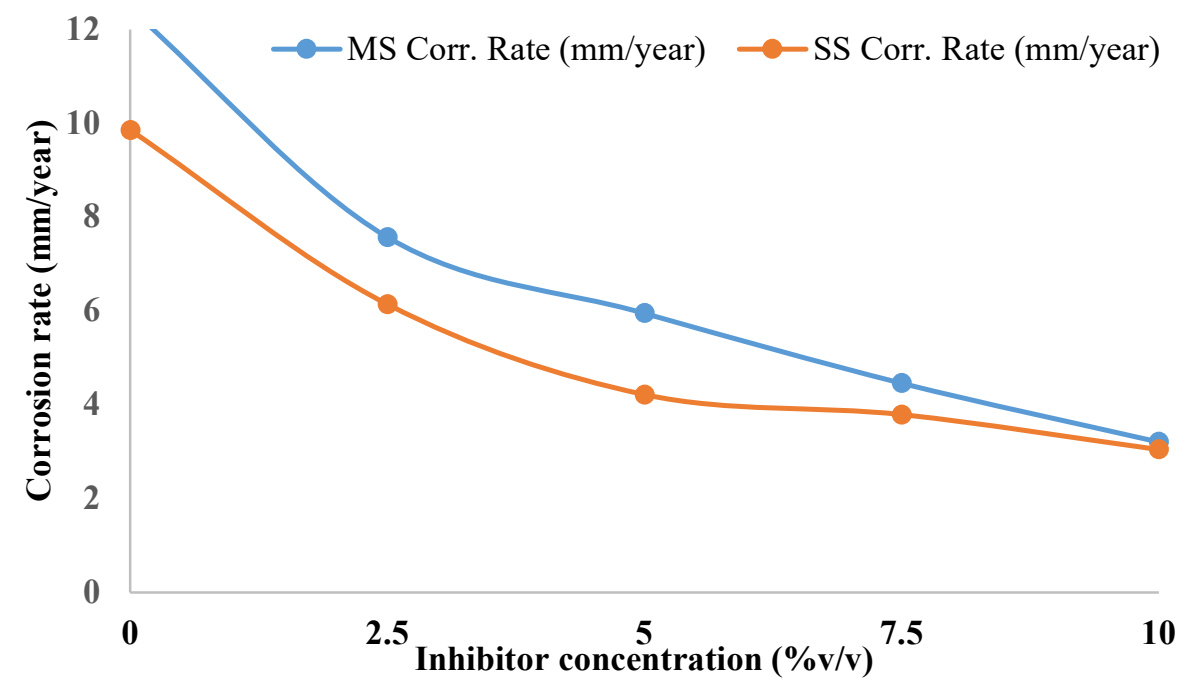

Fig.-5: Corrosion Rate of the Mild Steel and Stainless Steel at varying Inhibitor Concentrations

To establish the suitability of Langmuir isotherm for the prediction of the adsorption mechanism of pawpaw fluid inhibitor on the metal surface, the slope of the plot a plot of $C / \theta$ against $C$ has to give a value of one ${ }^{10}$. A plot of $C / \theta$ against $C$ (using Eqn.-5) gave a linear graph plot with regression coefficients $\left(R^{2}\right)$ of approximately one, as shown in Tables-3 and 4, a confirmation of the fitness of the Langmuir isotherm model in the prediction of the adsorption mechanism. Thermodynamic parameters, $K_{a d s}$ and $\Delta G_{a d s}$, were determined using Eqn.-5 and 8.

Table-3: Adsorption Parameters from Langmuir Isotherm for Stainless Steel

\begin{tabular}{c|c|c|c|c}
\hline $\begin{array}{c}\text { Time } \\
\text { (Days) }\end{array}$ & $\begin{array}{c}\text { Inhibitor } \\
\text { Concentration, } \mathrm{C}\end{array}$ & $R^{2}$ & $\begin{array}{c}\text { Adsorption } \\
\text { Constant, } K_{\text {ads }}\end{array}$ & $\begin{array}{c}\text { Gibbs Free Energy } \\
\left(\Delta G_{\text {ads }}, \mathrm{kJ} / \mathrm{mol}\right)\end{array}$ \\
\hline 3 & 1.8409 & 0.9851 & 0.5432 & -8440.3918 \\
\hline 6 & 2.0835 & 0.9689 & 0.4710 & -8086.9781 \\
\hline 9 & 1.0324 & 0.9888 & 0.9686 & -9873.6136 \\
\hline 12 & 8.2048 & 0.9025 & 0.1219 & -4737.5470 \\
\hline 15 & 10.6710 & 0.9763 & 0.0937 & -4085.5733 \\
\hline 18 & 3.5549 & 0.9567 & 0.2813 & -6809.7172 \\
\hline 21 & 1.2294 & 0.9748 & 0.8134 & -9440.8804 \\
\hline
\end{tabular}

Table-4: Adsorption Parameters from Langmuir Isotherm for Mild Steel

\begin{tabular}{c|c|c|c|c}
\hline $\begin{array}{c}\text { Time } \\
\text { (Days) }\end{array}$ & $\begin{array}{c}\text { Inhibitor } \\
\text { Concentration, C }\end{array}$ & $R^{2}$ & $\begin{array}{c}\text { Adsorption } \\
\text { Constant, } K_{a d s}\end{array}$ & $\begin{array}{c}\text { Gibbs Free Energy } \\
\left(\Delta G_{a d s}, \mathrm{~kJ} / \mathrm{mol}\right)\end{array}$ \\
\hline 3 & 1.0161 & 0.9643 & 0.9842 & -9913.2059 \\
\hline 6 & 2.0265 & 0.9857 & 1.1143 & -10220.8582 \\
\hline 9 & 1.9110 & 0.9933 & 0.5233 & -8347.9055 \\
\hline 12 & 4.4062 & 0.9734 & 0.2471 & -6488.4952 \\
\hline 15 & 6.9015 & 0.9511 & 0.1449 & -5165.8546 \\
\hline 18 & 1.5990 & 0.9681 & 0.6254 & -8789.5789 \\
\hline 21 & 1.8129 & 1.0223 & 0.5516 & -8478.4184 \\
\hline
\end{tabular}

The values obtained for $\Delta G_{a d s}$ are seen to be quite large values (with negative sign), an indication of the high rate of adsorption of inhibitor on the metal surface as well as physio-sorption (physical adsorption) mechanism. ${ }^{9,20-21}$ That is, it is a fact that negative values of $\Delta G_{a d s}$ usually connotes a spontaneous process as well as the existence of an electrostatic bond amongst the inhibitive molecules and the metal surface, 
RASĀYAN J. Chem.

Vol. 14 | No. 4 |2506-2515| October- December | 2021

this is also called physisorption. ${ }^{21}$ The values obtained for the free energy adsorption, $\Delta G_{a d s}$ are significantly lower than the value of $-40 \mathrm{~kJ} / \mathrm{mol}$ required for chemisorption, which shows that the adsorption process of the pawpaw fluid on the metal surfaces is natural and it is in agreement with the mechanism of physical adsorption. ${ }^{20}$

\section{Surface Coverage Results}

The corrosion resistance of both A315 mild steel and 304 stainless steel can also be explained in terms of the values of the surface coverage obtained. From Fig.-7 $(a-b)$, it can be observed that as the concentration of the inhibitor increased, the surface coverage of the inhibitor increased (for the two forms of a metal considered). This implies that the increase in inhibitor concentration caused an increase in thickness of the barrier formed on the surface of the metals; the thicker the layer thickness, the slower the corrosion process. This is because the barrier inhibits the ease of the occurrence of corrosion reactions from taking place ${ }^{21}$. Also, it can be observed from Fig.-7 $(a-b)$ that the rate of surface coverage by the inhibitor reduced with time, for each of the concentrations considered. That is, the level of aggressiveness of pawpaw fluid in inhibiting corrosion process reduced with time (for each concentration); a confirmation of the results obtained from weight loss (Figs.-1 and 2). That is the metal pores were easily and quickly occupied by the molecules of the inhibitor when the inhibitor was initially introduced. Comparatively, a keen observation of Fig.-7(a and b) showed that the higher values of surface coverage of the stainless made stainless steel more effective when related to the corresponding results obtained from mild steel (under the same experimental condition).
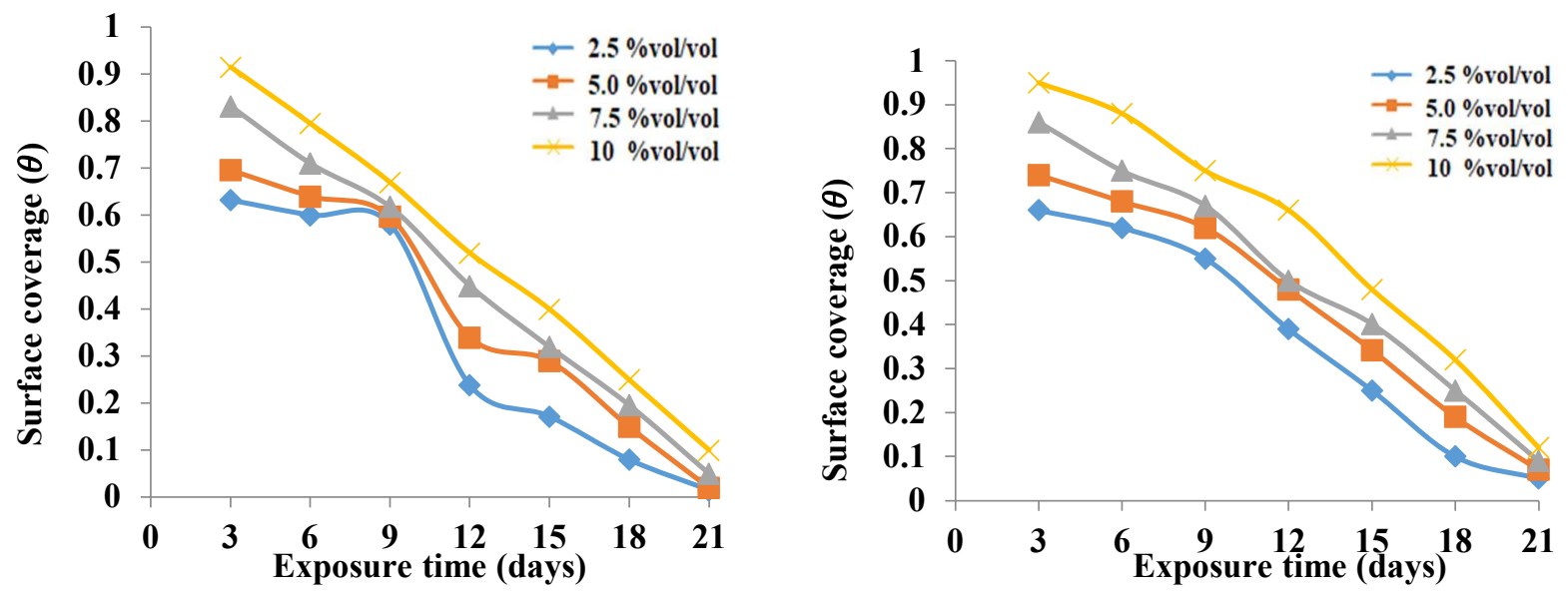

Fig.-7: Surface Coverage against Exposure Time (a) Mild Steel and (b) Stainless Steel

\section{Surface Morphology of the Samples after Corrosion}

Figures- 8 and 9 show the structural morphology of the mild steels and stainless steels (respectively, after 21 days of exposure to corrosion at different inhibitor concentrations.

In Fig.-8(i-v), it could be seen that the degree of the corrodibility of the mild steel samples decreased with an increase in the inhibitor concentration. That is, the sample with $0 \% \mathrm{vol} / \mathrm{vol}$ inhibitor concentration suffered corrosion most while the sample with $10 \% \mathrm{vol} / \mathrm{vol}$ concentration had the least impact of corrosion. The level of surface rupture and pit corrosion reduced with an increase in the application of the inhibitor. This further confirmed the fact that the corrosion resistance of the inhibitor increased with increased concentration by blocking the active site for corrosion reaction. ${ }^{22-25}$ A similar trend was observed for stainless steel samples in Figs.-9(i to v). Comparing Figs.-8 and 9, the impact of corrosion was more pronounced on mild steel samples when relate to stainless steel with the same experimental conditions. Hence, stainless steel shows better corrosion resistance properties compared to mild steel. And this attribute is traceable to the presence of a higher concentration of chromium and nickel (corrosion-resistant materials) in stainless steel. ${ }^{19}$ 
RASĀYAN J. Chem.

Vol. 14 | No. 4 |2506-2515| October- December | 2021
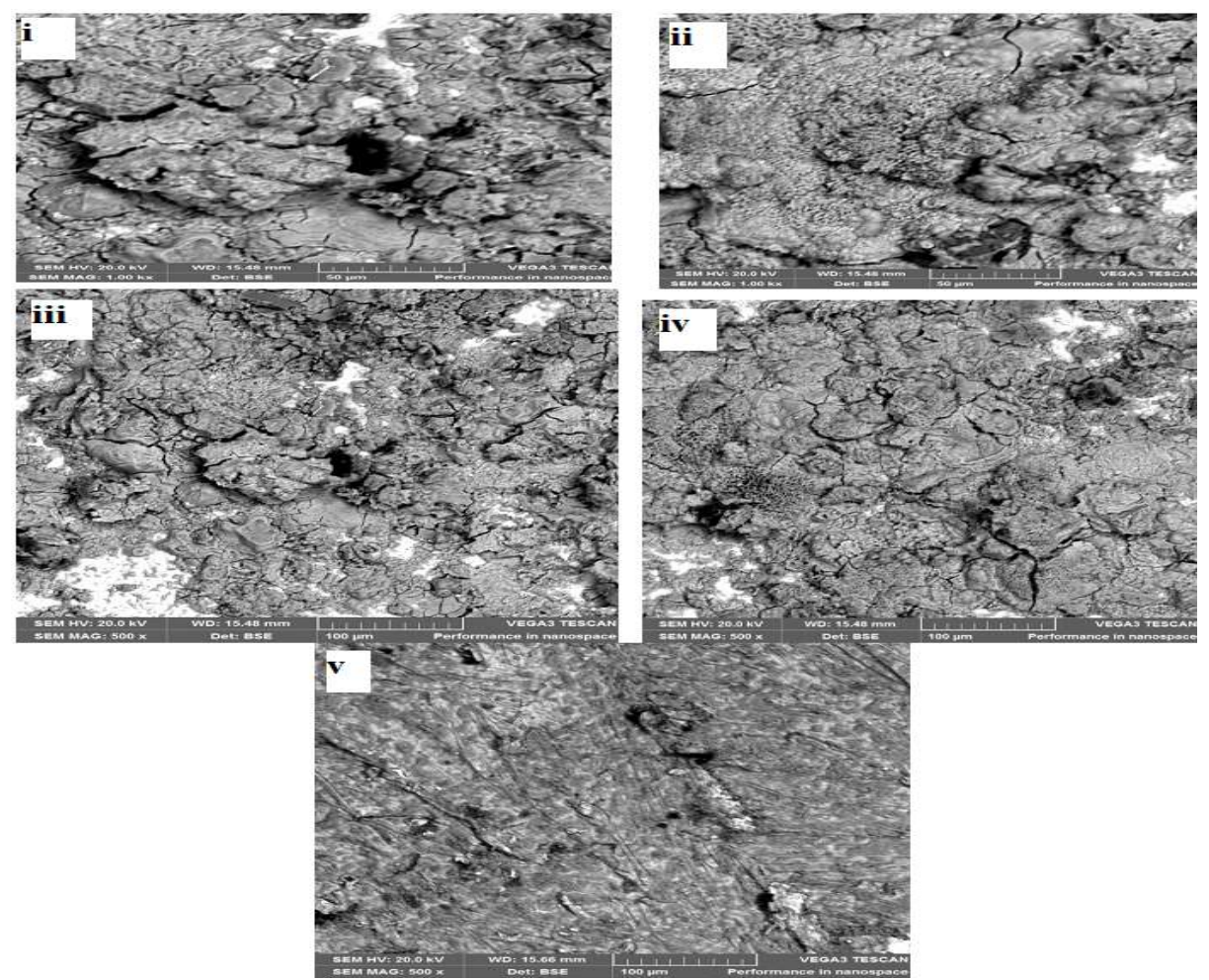

Fig.-8: Structural Morphology of Mild Steels with Inhibitor Concentration of

(i) $0 \% \mathrm{vol} / \mathrm{vol}$, (ii) $2.5 \% \mathrm{vol} / \mathrm{vol}$, (iii) $5.0 \% \mathrm{vol} / \mathrm{vol}$, (iv) $7.5 \% \mathrm{vol} / \mathrm{vol}$ and (v) $10 \% \mathrm{vol} / \mathrm{vol}$
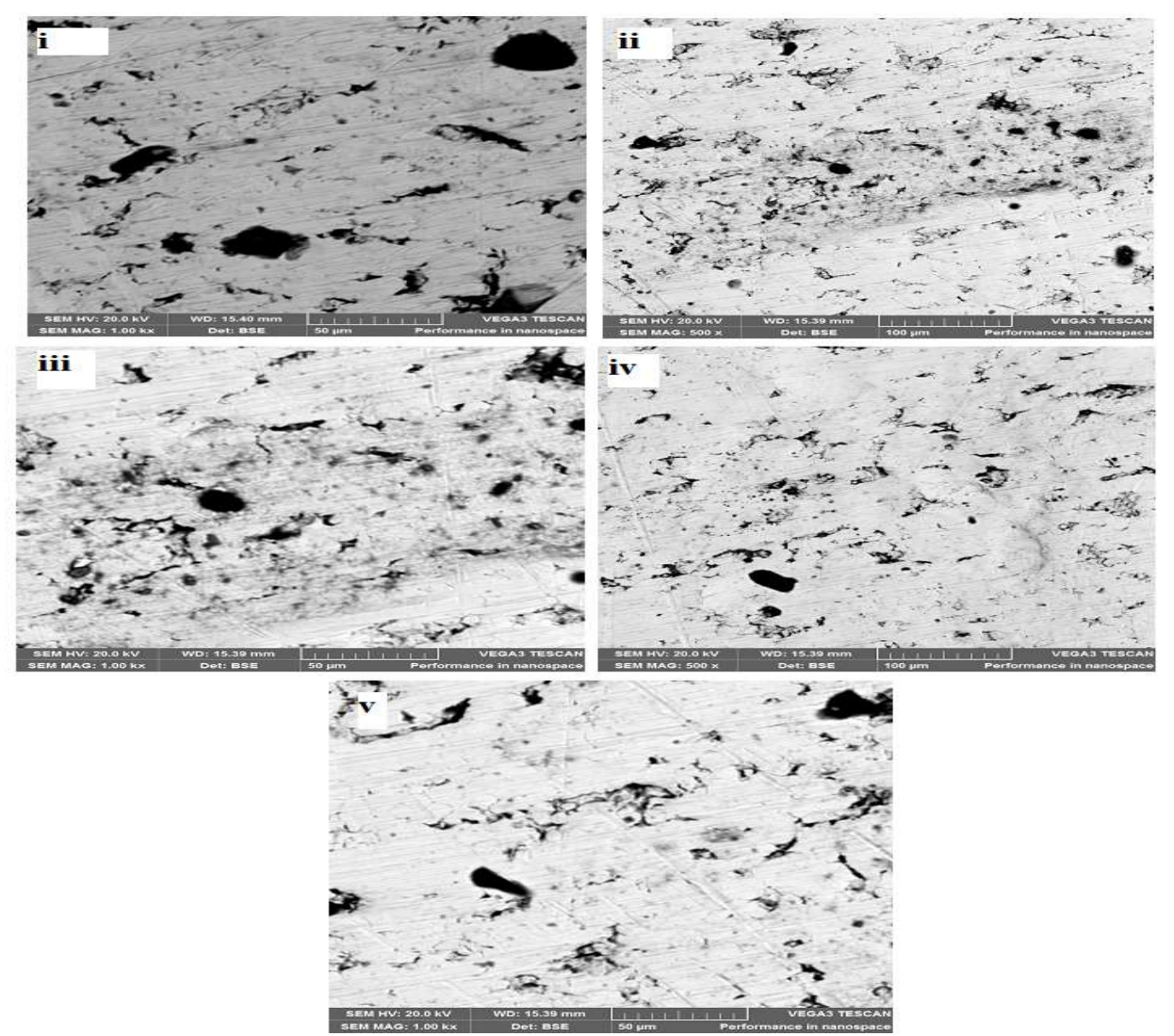

Fig.-9: Structural Morphology of Stainless Steels with Inhibitor Concentration of

(i) $0 \% \mathrm{vol} / \mathrm{vol}$, (ii) $2.5 \% \mathrm{vol} / \mathrm{vol}$, (iii) $5.0 \% \mathrm{vol} / \mathrm{vol}$, (iv) $7.5 \% \mathrm{vol} / \mathrm{vol}$ and (v) $10 \% \mathrm{vol} / \mathrm{vol}$ 
RASĀYAN J. Chem.

Vol. 14 | No. 4 |2506-2515| October- December | 2021

\section{CONCLUSION}

In conclusion, the following statements deduce from the research work:

i. Pawpaw fluid was successively used as a good corrosion inhibitor for the two forms of steels in $0.5 \mathrm{M} \mathrm{H}_{2} \mathrm{SO}_{4}$ medium.

ii. Pawpaw fluid with a concentration of $10 \% \mathrm{vol} / \mathrm{vol}$ gave the highest inhibitor efficiency of $89.9 \%$ and $87.1 \%$ for mild and stainless steels respectively and the least corrosion rate for the two forms of the metal samples.

iii. Results obtained revealed that the adsorption isotherm of Langmuir accurately described the behavior of the adsorption mechanism and the physical adsorption (spontaneous) nature of the inhibitor was justified by the negative values of $\Delta G_{a d s}$.

iv. Chemical composition results and the SEM analysis revealed that stainless steel has better corrosion resistance performance in $0.5 \mathrm{M} \mathrm{H}_{2} \mathrm{SO}_{4}$ medium compared to mild steel.

\section{ACKNOWLEDGEMENT}

The publication of this research work was made possible through the financial support of Covenant University CUCRID.

\section{REFERENCES}

1. O. Ajayi, O. Omotosho, K. Ajanaku and B. Olawore, Environmental Research Journal, 5, 163(2011)

2. I. Hanafi, A. Daul and S. Radiman, 35, 1(2017), https://doi.org/10.4152/pea.201701001

3. O.O. Joseph, O.S.I. Fayomi, A.O. Inegbenebo and A.A. Ayoola, Portugaliae Electrochimica Acta, 39, 159(2021), https://doi.org/10.4152/pea.2021390301

4. O.S.I. Fayomi, A.P.I. Popoola, O.O. Ige, A.A. Ayoola, Asian Journal of Chemistry, 29(12), 2575(2017), https://doi.org/10.14233/ajchem.2017.20659

5. A.A. Ayoola, N. Auta-Joshua, B.M. Durodola, O.J. Omodara, E.A. Oyeniyi, AIMS Energy, 8,130(2021)

6. I.T. Tuleum, J.D. Amine and K. Abubakar, American Journal of Material Science and Engineering, 2, 54(2014).

7. R.T. Loto, C.A. Loto and AP Popoola, South African Journal of Chemistry, 68, 105(2015), https://dx.doi.org/10.17159/0379-4350/2015/V68A16

8. N.A. Khalil, F. Mahgoub, B. Abd-El-Nabey and A. Abdel-Aziz, Corrosion Engineering Science\& Technology, 38, 205(2003), https://doi.org/10.1179/147842203770226933

9. R.T. Loto and O. Olowoyo, South African Journal of Chemical Engineering, 26, 35(2018), https://doi.org/10.1016/j.sajce.2018.09.002

10. N. Zidane, Y. Ait Albrimi, A. Ait Addi, R. Ait Akbour, J. Douchi, A. Nahle and M. Hamdani, Portugaliae Electrochimica Acta, 33, 289(2015), https://doi.org/10.4152/pea.201505289

11. L. Guo, J. Tan, S. Kaya, S. Leng, Q. Li, F. Zhang, Journal of colloid and interface science, 570, 116(2020).

12. R.T. Loto, Journal of Bio- and Tribo-Corrosion, 4, 47(2018), https://doi.org/10.1007/s40735-018$0163-y$

13. D.A. Winkler, Metals, 7, 553(2017)

14. J.H. Potgieter, P. Olubambi and S.S. Potgieter-Vermaak, International Journal of Electrochemistry,1(2014), https://doi.org/10.1155/2014/594871

15. A.A. Ayoola, O.S.I. Fayomi, I.G. Akande, A.O. Ayeni, O. Agboola, O.R. Obanla, O.G. Abatan and C.J. Chukwuka, Journal of Bio \& Tribo Corrosion, 6, 1(2020), https://doi.org/10.1007/s40735-02000361-y

16. A. Dehghani A, G. Bahlakeh, G. and Ramezanzadeh, Bioelectrochemistry, 130, 1(2019), https://doi.org/10.1016/j.bioelechem.2019.107339

17. N.A. Odewunmi, S.A. Umoren, Z.M. Gasem, S.A. Ganiyu, Q. Muhammad, Journal of the Taiwan Institute of Chemical Engineers, 51, 177(2015), https://doi.org/10.1016/j.jtice.2015.01.012

18. E.A. Noor, International Journal of Electrochemical Science, 2, 996(2007)

19. S. Arora, B. Sharma, C. Srivastava, Surface and Coating Technology, 398, 126083(2020) https://doi.org/10.1016/j.surfcoat.2020.126083 


\section{RASĀYAN J. Chem.}

Vol. 14 | No. 4 |2506-2515| October- December | 2021

20. P. Kumar, A.N. Shetty, 31, 21(2013), https://doi.org/10.4152/pea.201301021

21. D. Ringot, B. Lerzy, K. Chaplain, J.P. Bonhoure, E. Auclair and Y. Larondelle, Bioresource Technology, 98, 1812(2007), https://doi.org/10.1016/j.biotech.2006.06.015

22. A. Khadraoui, A. Khelifa, H. Boutoumi, B. Mettai, Y. Karzazi. B. Harmmouti, Portugaliae Electrochimica Acta, 4, 295(2014), https://doi.org/10.4152/pea.201404271

23. E. P. Untari and M. Efdi, Rasayan Journal of Chemistry, 14(1), 569(2021), http://dx.doi.org/10.31788/RJC.2021.1415836

24. K. Budipramana, K.R. Wirasutisna, M.W. Wartono, Y.B. Pramana, S. Sukrasno and T.A. Yuniarta, Rasayan Journal of Chemistry, 14(1), 149(2021), http://dx.doi.org/10.31788/RJC.2021.1415813

25. J. Jiang, C. Zhao and G. Li, Coatings, 10, 1(2020), https://doi.org/10.3390/coatings10010001

[RJC-6352/2021] 